\title{
Efeitos do medial em A guerra dos bastardos (2007) de Ana Paula Maia
}

\author{
Christiane Quandt ${ }^{1}$
}

Em seu ensaio L'éf fet de réel, Roland Barthes escreve sobre o luxo da narrativa que faz com que um texto nos forneça a ilusão de uma realidade ficcional, fazendo-nos entrar em um mundo alternativo. Barthes se pergunta se esse luxo da descrição é necessário e chega à conclusão que não se trata de detalhes supérfluos, mas sim de descrições ou evocações com valor estético e discursivo que em si seguem uma série de regras de representação sem visar dar uma imagem da própria realidade. Isto quer dizer que o leitor é capaz de entender a passagem em questão devido ao processo de referência à referência e não por causa da referência a uma realidade, continuando e modificando, em analogia a Barthes, uma tradição de recepção e estética, cujo sentido não se encontra na analogia a uma realidade, mas na repetição variada de uma tradição de representação, como por exemplo, imagens ekphrásticas em textos literários (Barthes 1968).

A hipótese deste trabalho é que há um efeito em alguns aspectos análogo ao éffet de réel nas referências intermidiais na recente obra A guerra dos bastardos (2007) da jovem autora de roteiro, teatro e, principalmente, de literatura 'pulp', Ana Paula Maia. O livro em questão é o segundo de, até o momento, cinco novelas da autora que também tem publicado contos em várias antologias e criou o primeiro "folhetim pulp" brasileiro em www.folhetimpulp.blogspot.com.

\footnotetext{
${ }^{1}$ Tradutora e doutoranda em Literatura pela Freie Universität Berlin.
} 
Em A guerra dos bastardos, salta à vista o diálogo com vários mídia. Desde filmes elitistas de vanguarda até a indústria pornô, passando por clássicos da literatura como Dostoiévski ou música como Abba, encontramos uma vasta gama de referências e representações de outros meios de comunicação. Em seguida, desejo analisar algumas dessas referências e presenças, para entender melhor como funciona a intermidialidade literária neste caso específico.

\section{Intermidialidades literárias}

A presença de outros meios de comunicação em expressões artísticas, literárias, cinematográficas não é um fenômeno apenas contemporâneo. Desde a antiguidade se escreve sobre a descrição de obras de arte visual ou a musicalidade de textos (Rajewsky 2002: 1-5). Posteriormente, os jogos e os entrelaçamentos de diferentes formas de expressão se manifestaram de forma marcante nas vanguardas dos anos 20 do século passado como no Futurismo italiano, no Estridentismo mexicano ou, também, no Modernismo brasileiro ${ }^{2}$. Também nas artes mais recentes se encontram performances multimídia, textos intermidiais e múltiplas outras formas de expressão com vários mídia involvidos. Também as várias metáforas musicais e visuais que se utilizam na análise literária como a polifonía de Bakhtin ou a escrita fílmica, o 'camera eye', ou inclusive a 'perspectiva' narratológica mostram uma difusa proximidade da literatura aos outros mídia (música, filme, fotografia). A partir dos anos 60, ou seja com o final da chamada modernidade literária, começam a manifestar-se cada vez mais frequentemente

\footnotetext{
${ }^{2}$ Refiro-me por um lado à multiplicidade das expressões artísticas (poesia, literatura, artes plásticas, música etc.) e por outro às próprias misturas inter e transmidiais como "Circuladô de fulô", texto de Haroldo de Campos de seu livro poético Galáxias, interpretado por Caetano Veloso.
} 
diálogos, contatos e transições entre os novos mídia (TV, rádio, cinema, e mais tarde internet, seus blogues e e-books) e a literatura, tanto na Europa como no continente americano $^{3}$. Esse novo fenômeno foi sendo denominado de intermidialidade ${ }^{4}$ Na literatura mais recente da América Latina e especialmente do Brasil não surpreende que na atual era dos mídia digitais a escrita intermídia continua sendo uma vertente cada vez mais forte. (vide Klengel et al. 2013: 14, 42ss)

No âmbito da literatura e das referências aos outros mídias a italianista alemã Irina O. Rajewsky fornece ferramentas adequadas e exatas para a análise. Em primeiro lugar, ela diferencia Transmidialidade ${ }^{5}$, que inclui fenômenos medialmente não específicos que se expressam em diferentes mídia (adaptação de novela em filme ou radionovela, versão infantil de clássicos da literatura etc.), de Intramidialidade, que inclui fenômenos como a intertextualidade que acontecem somente em um meio de comunicação (textos que se referem a textos, filmes que se referem a filmes etc.), e de Intermidialidade, que inclui fenômenos de diálogos e representações de vários mídia dentro de um meio específico, em nosso caso, a literatura (referência a filmes, música, teatro etc. na literatura e vice versa). Dentro da categoria Intermidialidade, a autora diferencia outra vez entre Referências intermidiais (Intermediale Bezüge), Mudança de mídia (Medienwechsel) e Combinação de mídias (Medienkombination). Dado que se trata de um texto literário que está repleto de referências a outros mídias, esta será a categoria relevante. Rajewsky diferencia ainda entre as várias formas de referência e fornece categorias exatas e relevantes para a análise a seguir.

\footnotetext{
${ }^{3}$ Herrmann Herlinghaus dá uma magnífica introdução à situação da América Latina entre 'Modernidade periférica' e Posmodernidade na introdução ao seu livro Intermedialität als Erzählerfahrung (Intermidialidade como experiência narrativa) partindo do exemplo do Chile.

${ }^{4}$ Também se encontra intermedialidade.

5 Para destacar os termos tomados de Irina Rajewsky e traduzidos ao português por mim, estão escritos com maiúscula.
}

RRASILIANA- Journal for Brazilian Studies. Vol. 3, n.2 (March, 2015). ISSN 2245-4373. @) (ब) ब( 


\section{Os bastardos e os mídias}

A densa e humorística trama de A guerra dos bastardos nos conta, desde a perspectiva de Dimitri $^{6}$, funcionário de uma videolocadora e narrador em algumas ocasiões intradiegético (volto a este ponto mais abaixo), a história de uma bolsa de cocaína e dos diversos personagens que acompanham o caminho do conteúdo da bolsa. Em um milieu de 'bastardos' de classe baixa criminosa, o leitor vai conhecendo a luta pela sobrevivência de Amadeu, um ator pornô, Horácio, um assistente da diretora de cinema vanguardista Edwiges D'Lambert, Gina Trevisan, uma boxeadora tatuada e semi-legal e namorada de Amadeu, Pablo Sasaki, assistente de Edgar Wilson ${ }^{7}$ e amante da namorada de seu chefe Zeferino Manches, conhecida como Greice Sally e que, por sua vez, é uma famosa artista anal e atriz pornô, um cachorro chiuahua e vários outros personagens (vizinhos, policiais e outros transeuntes) mais ou menos afortunados.

Para resolver uma dívida que Gina Trevisan tem com Zeferino Manches, Amadeu pede dinheiro a Salvatore, um gangster sem escrúpulo algum, mas este morre inesperadamente de um ataque cardíaco depois de executar um indivíduo chamado Aluísio devido a sua dívida com ele. Entre os dois mortos está a bolsa vermelha com cocaína na qual Amadeu vê a oportunidade de sua vida. Com a ajuda de Guilherme Benigno, outro personagem do mundo do cinema com projeto atual na favela, consegue vender a cocaína à diretora Edwiges D'Lambert no meio do set, em uma igreja. Logo, Amadeu esconde o dinheiro em um sótão alugado a um velho chamado Lozonni e morre em um acidente de tráfico no qual estão envolvidos Horácio, um taxista, e Edgar

\footnotetext{
${ }^{6}$ Vale mencionar que todos os personagens levam nomes que podem ser lidos como referências tipo pastiche a figuras literárias e filmicas.

${ }^{7}$ Edgar Wilson aparece em vários outros textos da autora como personagem.
} 
Wilson acompanhado por Pablo Sasaki (mas isso só chegamos a saber depois). Dado que Gina não recebeu a informação sobre o dinheiro antes de Amadeu morrer, ela tenta conseguir o dinheiro por meio de uma luta ilegal contra Hugo Valentino, um boxeador famoso, que termina em coma. Por isso, Gina tem que fugir e a sua fuga termina no apartamento de Horácio, sem ela saber que Amadeu vivia aí pouco tempo antes. Com vários interlúdios mais ou menos absurdos, estranhos e humorísticos, Pablo, Dimitri, o cachorro, Edgar, Gina e o cadáver de Lozonni (e mais um cadáver 'produzido' no processo) e ainda Horácio terminam em um carro a caminho do hospital para Gina identificar Amadeu e para logo fazer contas finais. No final do texto, depois de os corpos de Lozonni e do policial tenente Miranda serem devorados por porcos, voltamos para a perspectiva de Dimitri que enquadra o argumento. Ele se encontra em Ushuaia acompanhado pelo seu irmão adotivo Edgar Wilson, no meio do nada e da neve.

Em várias ocasiões se dá a presença mais ou menos óbvia de meios de comunicação como rádio, televisão, filme em dvd (e ao 'vivo'), filme no cinema, CD de música etc. Primeiro salta à vista que a maioria das figuras principais trabalham na criação, distribuição ou produção cinematográfica. Amadeu é ator pornô “Há dois anos trabalha como ator pornô nos estúdios de Zeferino Manches (....). Ganha razoável, o correspondente ao tamanho do seu pênis." (p. 22 ${ }^{8}$ ), Dimitri trabalha em uma videolocadora onde vê filmes de todo tipo todo dia: "Antes de tudo isso, eu era apenas um funcionário frustrado e mal-humorado numa videolocadora." (Maia 2007: 17), Zeferino Manches é dono do estúdio pornô onde também trabalha Greice Sally, e Horácio é assistente técnico de Edwiges D’Lambert, produtora de filme vanguardista, enquanto Guilherme Benigno está fazendo um filme 'independente' em uma favela.

\footnotetext{
${ }^{8}$ Todas referências e citações que somente levam o número da página são do texto primário $A$ guerra dos bastardos.
} 
Tanto os mídias primários como os secundários e terciários ${ }^{9}$, rádio filme e televisão, nos quais se focará a análise ${ }^{10}$, estão presentes nos diversos lugares e espaços da trama; por exemplo, o fato de o lutador de boxe Hugo Valentino estar em coma se apreende pelo rádio e pela TV: "Após a apresentação de uma reportagem sobre talentos do samba, a notícia ainda cheia de caroços e lacunas sobre o caso de Hugo Valentino repercute nos dois como ondas gigantes de um mar bravio (...)." (p. 173). Também se mencionam vários filmes e reportagens televisivas ficcionais e não ficcionais como “Desejo de matar partes 1,2 e 3" (p. 62), “(...) o filme Acossado de Jean-Luc Godard.” (p. 242), um filme de Bruce Lee (p. 112), uma reportagem sobre tubarões (em várias ocasiões), um dos filmes de Greice Sally onde ela exibe seu talento em expelir de sua bunda bolinhas em chamas, o qual uma personagem confunde com o espetáculo do Cirque du Soleil (p. 115), somente para mencionar alguns exemplos. Mas a referencialidade medial não termina aí, aparecem referências mais complexas e menos óbvias que sugerem a hipótese de uma leitura 'cinematográfica' do texto inteiro, ou seja, que podem ser lidos como referentes de um 'efeito do medial'. A seguir, analisarei algumas passagens do livro que representam várias formas de intermidialidades e que sustentam a hipótese do presente trabalho.

\footnotetext{
${ }^{9} \mathrm{Na}$ teoria dos mídias, segundo o teórico alemão Harry Pross, distingue-se entre mídias primários como a linguagem mímica e gestos, e dança, ou seja, mídias que não precisam de um aparelho técnico para transmitir sua mensagem; mídias secundários que são aqueles que precisam de ferramentas para serem fabricados, mas não para serem consumidos, por exemplo sinais de fumo, outros sinais visuais, imagens e textos escritos ou impressos, e música escrita ou praticada ao vivo; e ainda, os mídias terciários que tanto no lado da produção como no da recepção precisam de aparatos técnicos e não funcionam sem eles como filme, rádio, televisão etc. que por sua vez podem conter um ou vários mídias primários. (Hicketier 2010: 22, 23).

${ }^{10}$ Deixarei de lado o análise de imagens e música não transmitida tanto como as várias referências intertextuais.
} 


\section{Menções, Referências, Contaminações}

Segundo Rajewsky, as referências explícitas mencionadas caem sob a categoria de Referência única (Einzelreferenz) ou Menção de sistema (Systemerwähnung). Esta última pode ocorrer ou como Menção de sistema explícita (explizite Systemerwähnung) ou em forma de Transposição (Systemerwähnung qua Transposition). Essas formas de intermidialidade trazem os diversos meios de comunicação ao texto mencionando-as direta e explicitamente como no caso dos filmes e do rádio ou parafraseando-os com a ajuda das partes textualizáveis do outro meio. Os filmes mencionados, com excepção de Acossado, Desejo de matar e “(...) o último filme de Bruce Lee” (p. 109) não vão além de uma Referência única, dado ao fato que se mencionam somente sem outra referência explícita ao conteúdo ou aos personagens. Um exemplo de Reprodução (parcial) ((teil)reproduzierende Systemerwähnung), porém, seria a citação de uma canção de Abba: "O som do Abba. If I have to do the same again, I will my friend, Fernando." (p. 103) ou a longa citação de um locutor de rádio que fala de Hugo Valentino e termina com a seguinte especulação errônea, como sabem os leitores, "Acredita-se que a máfia de lutas clandestinas entre sexos opostos é manipulada por um grupo argentino."(p.187); um exemplo de uma Menção de sistema em forma de Evocação (evozierende Systemerwähnung) seriam as ocasiões, nas quais os mídias (TV ou rádio) informam sobre Hugo Valentino e não citam diretamente: “O repórter afirma não ter detalhes (...)" (p. 173) ou a reportagem sobre tubarões que Horácio e Amadeu vêem na TV: “Os tubarões capturados e envenenados sofrerão, pelo menos, uma semana até morrer, e têm todo oceano por corredor da morte." (p. 52). A terceira forma de Menção de sistema (Systemerwähnung) é a Menção de sistema em forma de simulação (Simulierende Systemerwähnung) que, mencionando o outro meio explicitamente e imitando-o ao mesmo tempo, produz uma ilusão dele, modificando a estrutura 
narrativa do texto para simular essa presença ${ }^{11}$. Encontramos essa forma intermidial na cena da morte de Amadeu que é atropelado pelo taxi de Horácio que o leva até o hospital. Mas Amadeu morre a caminho:

“(...) Ele tenta dizer algumas palavras e questiona-se sobre o que dizer na hora da morte. Pensa nos filmes e o que dizem os grandes atores, nas mortes históricas da vida real. Percebe que nunca pensou em sua morte, que não preparou um discurso sequer, que não há o que falar, ou legado para deixar. (...) Estendido sobre o banco, Amadeu sabe que é uma tragédia.

Considera aquela morte sua melhor performance. Nos últimos dias foi um ator de verdade, ainda que ninguém sabia. Ele estava tendo uma morte a que as massas adorariam assistir, uma morte de efeito, própria para a grande tela." (pgs. 94, 95)

Ao ler a passagem de quase dez páginas as imagens, algumas tão absurdas como uma orelha solta e perdida no acidente -talvez uma refeência a Blue Velvet de David Lynch?- são fortes em sua descrição e criam uma imagem quase cinematográfica já antes de se mencionar os "atores", a "tragédia" e a "morte de efeito própria para a grande tela". Com essas menções, dá-se uma simulação próxima a um filme que ademais sublinha o toque absurdo da situação, essa mistura de humor, estranheza e violência que marca o texto todo.

\footnotetext{
${ }^{11}$ Como afirma Rajewsky em várias ocasiões: não é possível levar um filme à literatura, tratar-se-a sempre de uma ilusão.
} 
Sob a categoria de Referência de sistema (Systemreferenz), cuja primeira subcategoria é a Menção de sistema (ver acima), encontra-se a outra subcategoria Contaminação de sistema (Systemkontamination) com as duas formas de Contaminação de sistema via traslação (Systemkontamination qua Translation) e Contaminação de sistema parcialmente atualizadora (Teilaktualisierende Systemkontamination). A grande diferença entre as formas de Menção de sistema e a Contaminação de sistema é que nestes últimos casos, o outro meio de comunicação é atualizado e utilizado como pano de fundo e mencionado pontualmente como na Menção de sistema durante todo texto. As formas como isso acontece velam-se necessariamente por meio de um efeito de ilusão dado ao fato de que um filme ou uma peça de música nunca poderá ser reproduzida de verdade em um texto escrito. Para conseguir essa ilusão, o texto utiliza as qualidades específicas do outro meio, entrelaçando-as no próprio texto não somente em certas ocasiões, mas durante longas passagens ou inclusive no texto inteiro. Assim, o leitor obtém uma efeito 'cinematográfico' ou 'musical' de um texto literário. Em A guerra dos bastardos essa forma de intermidialidade mais complexa está presente. Se olhamos para a morte de Amadeu em sua totalidade, poderíamos também categorizá-la como Contaminação parcialmente atualizadora (Teilaktualisierende Systemkontamination). Um indicador dessa forma de contaminação intermidial é a utilização do presente como tempo narrativo que é o caso na passagem em questão e, a apropriação das regras do sistema de referência, ou seja, as sequências de imagens descritas, quase cinematográficas, na hora da morte do ator pornô Amadeu: "Horácio, atônito, sustenta Amadeu em seus braços e limpa o sangue que escorre de sua boca." (p. 89), "Horácio depressiona seu ventre. Vê suas entranhas expostas (...)” (p. 91), “Chegam ao hospital e o taxista sempre murmurando (...)" (p. 96). Assim se dá uma aparente simultaneidade entre o tempo narrativo e o tempo narrado que, em conjunto com as imagens 
impactantes e coloridas, desconstrói o discurso narrativo literário criando a ilusão de um discurso fílmico que se vela de ferramentas fílmicas (Rajewsky 2002: 128).

Outra passagem do texto que descreve a luta ilegal de Gina Trevisan contra Hugo Valentino também contribui para a Contaminação de sistema do texto, esta vez em forma de Atualização parcial, onde o outro meio e o meio literário, ou seja, a 'realidade' ficcional, se misturam e o outro meio se torna base estética e 'técnica' do texto. Neste caso, o meio de contaminação também é o filme, cuja estética visual é, outra vez, imitada por meio de descrições de cores vivas, pelo discurso narrativo no presente e, utilizando passagens de diálogo em linguagem cotidiana, inclusive vulgar. Gina é levada ao local da luta por um amigo, Elvis Wanderley, que a esperará depois no carro. Ela prometeu lutar e perder contra Hugo Valentino (promessa que, como sabemos, não cumprirá), depois de ele ter vencido duas outras mulheres, Clara Ribeirinha e Anita Moenda.

“Chegam no local da luta, nos fundos de uma boate de Zeferino Manches, no Centro da cidade. Elvis permanece em seu carro e Gina entra sozinha. Nem sinal de Hugo. Alguns sujeitos conversam e bebem no também improvisado bar, próximo ao ringue. (...) Gina respira fundo. A cada palavra saída da boca de Anita, arrepende-se de estar ali. A outra lutadora pede para que Anita pare de falar. Zeferino entra no vestiário, girando o toco de charuto na boca e dizendo: "Então, meninas? Botando papinho em dia? Espero que estejam bem dispostas.(...)" Uma hora da tarde. (...) A música pára. Gyro faz as apresentações. Hugo e Ribeirinha iniciam uma dança (...) Gina Trevisan sabe que será massacrada, que aquilo é uma carnificina, e ela quer desistir. (...) "Três mil e você sobe." Ele sai do vestuário e vai até o 
escritório da boate. Retorna minutos depois com um envelope amarelo timbrado (...)" (pgs. 152-160).

Logo que Gina recebe o dinheiro de Zeferino, segue-se a descrição da luta entre Gina e Hugo, depois da qual Gina foge com a ajuda de Elvis Wanderley:

“Essa é a luta mais esperada. Gina tem um nome importante, ainda que sem nenhuma aquisição de títulos nos últimos tempos. Hugo, um pouco fatigado por causa de Anita Moenda, sente-se refeito para encará-la. Um corte no rosto e um inchaço. (...) Gyro autoriza o início do assalto. Eles se estudam, em movimentos ponderados, giram ao redor do outro. Gina tem uma ótima envergadura, Hugo é preciso nos golpes. (...) Vários socos arrebentam a cabeça de Hugo. Quanto mais socos recebe, mais seu pau endurece, e ela sente o corpo dele relaxar, inerte, até espirrar sangue em seu rosto. Hugo não reage." (pgs. 161-163)

Mais um exemplo de Contaminação de sistema, também em forma de Traslação, talvez o mais importante e menos óbvio, é a estrutura de narração que com o prólogo e o último capítulo fornece um tipo de moldura narrativa. Nesses dois capítulos se apresenta Dimitri como narrador, desde Ushuaia no sul do Chile que sente a necessidade de contar essa história que é a trama principal de A guerra dos bastardos:

“(...) Alguma coisa tinha que acontecer e alguém distante iria interferir de modo não discreto em minha vida. Agora sou um pouco mais mal- 
humorado, a frustração ganhou proporções que não caberiam aqui, porém agora ganho sete vezes mais. É, dá pra viver com a parte ruim.

Mas estou longe de ser o protagonista nisso tudo, que nada, apenas um personagenzinho um tanto apagado, mas alguém precisa fazer isso, contar toda história. Eu poderia ter deixado de lado, mas o que há pra se fazer enquanto assisto através da janela a cordilheira dos Andes desabar violenta no mar? Deixei o Sudeste escaldante do Brasil e atingi a extremidade do sul da Argentina. A cidade do fim do mundo, Ushuaia, no extremo sul; gelado e desolado da Terro do Fogo. (...)" (pgs 17,18)

É bem interessante que aqui a focalização é interna e o narrador é autodiegético (conta sua própria história desde sua própria perspectiva). Mas isso muda radicalmente depois do prólogo até chegar ao capítulo 20. Durante a trama principal há muito poucas passagens onde essa constelação se repete - são aquelas onde Dimitri aparece como personagem e interage com os outros. Na maioria das sub-histórias e anedotas, ele não está presente, nem na realidade textual, nem a nivel narratológico como narrador autoou homodiegético. Em vez disso, o discurso da narração se converte em discurso de um narrador heterodiegético com focalização diferente dependendo da situação. Por exemplo durante a luta entre Gina e Hugo, o foco de perspectiva interna muda entre os dois lutadores, entram pensamentos e sentimentos tanto de Gina como de Hugo que ninguém fora deles mesmos pode conhecer. Esse fato indica uma forte proximidade a certo gênero de filme onde um narrador está presente no princípio, para se introduzir e conta uma história de outros personagens, na qual ele mesmo se converte em um personagem entre muitos e desaparece como voz e imagem narradora durante a maioria do filme. Nos filmes que se servem dessa técnica de moldura, o narrador aparece ao 
princípio na sua situação atual e logo vem a parte da história que ele conta em retrospectiva, como filme principal (com a câmara como narradora). No final, aparece outra vez o narrador na mesma situação do princípio que conclui a história. Às vezes, aparece a voz do narrador durante a história principal, outras não. Neste exemplo, a proximidade ao filme é quase chocante, a Translação do meio literário a uma forma fílmica acontece tão clandestinamente que até ao leitor é quase imperceptível.

\section{O efeito dos outros mídias}

Os efeitos da presença dos outros mídias neste livro são vários. Dado à ironia e estranheza humorísticas permanentemente presentes no texto, alguns dos recursos intermidiais criam e reforçam essas características, ao passo que em outras ocasiões os mídias parecem ilustrar ou criar rupturas com aquilo que acontece no discurso narrativo de primeiro nível.

\section{Entre ironia e reforço}

Entre as várias Menções de sistema encontram-se algumas que se poderiam subsumir como rupturas entre irônicas e reforçantes. Nem sempre fica claro se o cinismo e a brutalidade fazem parte de um discurso irônico ou reforçam o ar de violência e falta de escrúpulos do texto inteiro. Vejamos uns exemplos. Quando chegamos a saber do primeiro homicídio de Edgar Wilson, os recursos narrativos e intermidiais utilizados insinuam uma forte ironia. Edgar Wilson, depois de ser adotado pela mãe de Dimitri, tem seu primeiro trabalho como “(...) empacotador e moedor de ossos no mercadinho do bairro (...)" (p. 101) com dona Betinha como chefa que o maltrata e insulta 
constantemente. Finalmente, não aguenta mais e mata dona Betinha durante a missa do padre Sebastião Anchieta que escuta pelo rádio:

"Padre Sebastião Anchieta repetia várias vezes a Salve-rainha, o que o aborrecia um pouco. A mulher resultou em robustos e gordurosos bifes sangrentos, pois seus largos quadris produziam alimento para muitos dias de festa. (...) A missa acabou e ele trocou de estação. Resolveu moer logo os ossos da saca, cujos farelos são usados na fabricação de ração para cães. Entre a chiadeira das estações do rádio, um som agradável, uma música o toca profundamente, ainda que sem entender $\mathrm{o}$ significado. O som do Abba. If I have to do the same again, I will my friend, Fernando. Com os olhos lacrimejantes, emocionado, moeu toda a saca" (p. 103)

Aqui, o Salve-rainha do rádio cria um forte contraste com a realidade ficcional em primeiro nível onde o personagem está cometendo um homicídio cruel e sangrento. Esse contraste é ainda mais acentuado quando muda de estação e escuta 'Fernando' de Abba. A breve citação desta canção pode ser vista como premonição que marcará toda a vida de Edgar Wilson ${ }^{12}$, dado que afirma que vai fazer a mesma coisa de novo, se for preciso (ou seja, matar as pessoas que o maltratam). Como leitor sabemos que este oráculo se cumpriu, porque Edgar é agora um daqueles que 'resolve problemas', se for necessário cortando membros ou matando pessoas. Tanto a referência ao personagem feminino no discurso radiofônico do padre (a rainha virgem Maria) como a música doce do Abba que faz com que os olhos de Edgar lacrimejem podem ser lidos como forte ironia, que,

\footnotetext{
${ }^{12}$ Ainda mais irônico é o fato que Edgar não fala inglês.
} 
por sua vez, reforça o ambiente violento, sangrento e absurdo em que se movimentam os personagens.

Outra situação comparável, mas não tão extensa, se encontra depois da luta de Gina. Ela sai correndo até o carro de Elvis e dentro do carro "Ele liga o rádio e troca as estações. Uma rumba explode dentro do carro, ricocheteando nos vidros, sufocando o raciocínio. O sinal fecha. (...) "Você está bem?" “Eu vou vomitar", diz Gina." (pgs. 164165)

Aqui, a constelação intermidial é similar, mas o contraste entre a realidade narrada do primeiro nível e o outro meio de comunicação causa um mal-estar físico na protagonista; a rumba faz com que Gina vomite. Claro que essa causalidade não é unívoca (é mais provável que vomite por causa da luta), mas à primeira vista, o texto sugere-a. Também aqui a ironia é uma ironia quase cínica que causa um mal-estar no leitor, uma ironia dupla que tem um lado cínico e um lado gracioso que se entremesclam naquela náusea. Também no caso da morte de Amadeu se pode ver a referência cinematográfica como recurso irônico, quase cínico. Amadeu, ator pornô, por fim chega a dar uma performance digna de um filme, mas não é dentro de um filme, é na vida 'real' e será sua última, sua morte. O fato de ele perder sua orelha é mais um aspeto que lemos sem saber se rir ou chorar, e que contribui para o mal-estar nauseabundo. A presença de uma 'artista' como Greice Sally não precisa ser decifrada em suas caraterísticas irônicas, muito menos a confusão de seu show com o 'Cirque du Soleil'. E, finalmente, a figura de Edwiges D'Lambert que no próprio set de seu filme bem complexo e vanguardista que nunca respeita o roteiro, faz negócios de cocaína, utilizando, ainda por cima, sua perna protética para isso. Essa constelação também não carece de ironia e de cinismo, tão pouco como o fato de Horácio, assistente de Edwiges, se encontrar na mesma camada social que Amadeu, ator pornô medíocre. 


\section{Entre ilustração e ruptura}

Enquanto que nas partes acima descritas a ironia é caraterística presente, outras passagens, algumas delas já descritas, parecem carecer de ironia. Nesses casos os formatos mediais citados dão conta daquilo que acontece e funcionam como ilustração, de quando em vez inclusive como contraste ou ruptura, dado à força com a qual entram no discurso literário.

O primeiro exemplo é a luta de Gina contra Hugo que se assemelha a um filme, como vimos mais acima. Essa luta é séria, tão séria que não se sabe se Hugo vai sobreviver ou não, e neste caso, o fato de a passagem aparecer como Contaminação de sistema parcialmente atualizadora, sendo o meio contaminador o filme, reforça a tensão e puxa o leitor virtualmente para dentro do ringue, 'vemos' os lutadores, 'sentimos' o cheiro de suor e sangue e 'ouvimos' o barulho do público se misturando com a música de fundo ao ler o texto. É uma cena violenta e impressionante, apesar de o tesão (será ironia afinal?) de Hugo frente à beleza de Gina provavelmente quase ter-lhe custado a vida. O efeito de insegurança e da tensão prolonga-se pela falta de informação acerca do estado de saúde de Hugo. Essa lacuna se preenche pouco a pouco por passagens de rádio e TV que informam primeiro que Hugo está em coma e logo que está se recuperando. É impressionante a 'naturalidade' com a qual entram os discursos dos noticiários no texto, aumentando a tensão da história, por exemplo, quando Edgar Wilson e Pablo Sasaki estão avaliando a situação depois da luta no escritório de Zeferino Manches: “... O boxeador Hugo Valentino, de 25 anos, chegou ao hospital das Clínicas em estado de coma, dois dias antes de viajar para Miami (...)” (p. 186). Essa tensão e o valor da vida de Hugo se mostram a seguir no comentário de Zeferino: “O problema é o garoto. Se esse moleque morre aí sim preciso me preocupar. (...)” (p. 187). Por um lado, 
Hugo Valentino é filho de um personagem importante na política e é provável que Zeferino esteja envolvido em outros tipos de negócios (por exemplo apostas de luta). O fato que se trata de uma Reprodução parcial - a citação do discurso do locutor é direta sublinha outra vez o efeito do medial, assemelhando o discurso narrativo a uma imagem de filme que, por sua vez, utiliza o som do rádio como recurso narrativo.

Outro tipo de ilustração se dá no caso das Menções de sistema, ou seja, as menções de filmes que existem de fato no mundo extraliterário. Desejo de matar é mencionado como filme que Amadeu vê para passar o tempo quando está esperando uma resposta de Guilherme Benigno para ele lhe ajudar a vender a cocaína encontrada. Amadeu acaba de esconder a bolsa vermelha no sótão de Lozonni e fica esperando, um pouco nervoso, no apartamento de Horácio onde alugou um quarto:

“(...) Fez café duas vezes. Esvaziou a jarra duas vezes. Deu longas mijadas. Assistiu aos filmes Desejo de matar partes 1,2, e 3. Telefonou para Guilherme seis vezes até este se cansou e desligou o celular. Este é o dia e daqui a pouco ele atravessará a rua. Guilherme fora bastante eficiente." (pgs. 61-62)

À primeira vista, parece que a enumeração dos três filmes serve meramente para ilustrar o tempo que passou. Também aqui se poderia imaginar um trecho de filme que se baseia nas frases curtas e pontuais que caberiam bem em um roteiro. Mas parece que esta menção vai além de uma atualização esporádica do meio fílmico. Se olharmos para a trama dos três filmes Death Wish 1, 2 e 3, a complexidade da referência começa a revelar-se. Os três filmes dos anos 1974, 1982 e 1985 tratam a história do protagonista Paul Kersey (Charles Bronson) que, depois de sofrer um assalto no qual sua mulher morre e sua filha é violada, se converte em vigilante que por conta própria caça bandidos. Na segunda parte, ocorre um novo assalto que resulta na morte da filha, e ele faz a mesma coisa que na primeira parte, mas em outra cidade e na terceira parte Kersey 
inicia uma guerra aberta contra os bandidos na Eastside de Nova Iorque e inclusive com a ajuda (semi oficial) da polícia. Não só é o primeiro dos três filmes mencionados uma adaptação de um livro, ou seja, pertenceria à categoria de Transmidialidade, mas também se desenvolve em um ambiente de violência e crime como o texto de Ana Paula Maia. O fato de o filme dar a perspectiva da vítima que resolve seus problemas com a força da arma é semelhante à decisão de Amadeu que pegou a bolsa com a cocaína aproveitando a ocasião. Mas, em contraste ao protagonista do filme, Amadeu continua precisando de ajuda para aproveitar sua chance e finalmente fracassa morrendo em um acidente de tráfico. Será essa uma versão mais realista e, talvez, mais 'brasilieira' da auto-afirmação de uma vítima que se converte em autor de crime? Ou será que o texto formula assim, aparentemente sem muita importância, uma crítica à política que não consegue resolver o crime e a droga no Brasil? Ou será, finalmente, que a perspectiva do texto, em certo sentido contrária àquela do filme, atua como nota de rodapé para o filme, chamando atenção ao fato que os bandidos também são vítimas? A meu ver, é uma mistura de tudo isso e uma forma sutil e inteligente de abrir passo a um vasto campo de reflexão social-política que não só no Brasil deve ser constantemente pensada e repensada.

Para finalizar observemos a moldura narrativa que cerca a novela, a história de Dimitri que no primeiro nível temporal da narração está em Ushuaia com seu irmão adotivo, Edgar Wilson. Esse recurso formal tem uma mensagem semântica bem pessimista. Dimitri era um dos poucos personagens que tinha um trabalho decente e não criminoso em uma videolocadora. A consequência daquilo que acontece na trama do livro para Dimitri é uma mudança de vida, um novo oficio onde ganha "sete vezes mais" para compensar "a parte ruim" (p. 18). Essa moldura narrativa converte, a nível semântico, o livro inteiro em um relatório de fracasso de uma vida não criminosa e 
decente. De forma similar ao protagonista de Desejo de matar, o narrador do livro vê que a polícia não resolve os problemas que deveria e que ele sobrevive se tomar a 'justiça' nas próprias mãos. Edgar Wilson, como sabemos, sempre faria o mesmo de novo $^{13}$ (lembremo-nos de seu 'hino' de Abba), e agora também Dimitri se converte em bandido. Esse final pessimista faz com que o personagem de Dimitri sofra uma ruptura, uma reviravolta total, surpreendendo-nos com sua vida não criminosa 'antes' do prólogo, no qual sua nova identidade é revelada desde o princípio. E essa tensão faz parte substancial do texto, contribuindo para o mal-estar prazeroso da leitura.

\section{O trailer do livro: fenômeno trans-midial}

Além das inúmeras referências intermidiais do texto, o livro de Ana Paula Maia transgrede, de fato, os limites do meio literário. No âmbito de uma nova política publicitária de editoras brasileiras, vários trailers de livros são disponibilizados online. ${ }^{14}$ Segundo a sistemática de Irina Rajewsky, esse recurso cairia sob a categoria de Transmidialidade, como por exemplo adatação de livro a filme. O caso presente é um pouco mais complexo. Dado ao fato que o formato de trailer normalmente não se conecta com um livro, mas sim com um filme. Essa nova forma de trailer subverte a maneira tradicional, misturando duas midialidades de narrar, a áudio-visualidade do filme com a textualidade do livro, e apresenta um gênero híbrido que, com recursos fílmicos, representa um texto. Essa transgressão não é em todos os aspetos comparável a uma adaptação, porque a função de um trailer é outra que a função de um longa

\footnotetext{
${ }^{13}$ Também em outros textos de Ana Paula Maia.

${ }^{14} \mathrm{O}$ trailer de A guerra dos bastardos está disponível em: www.youtube.com/watch?v=UhJuLghrrH8. E atualmente está sendo feito um filme do livro.
} 
metragem. O trailer deve dar uma concisa representação de um filme que faz com que o público fique com curiosidade der ver o produto inteiro. O trailer de um livro tem uma tarefa mais difícil porque utiliza recursos de filme para criar curiosidade necessária para a leitura, correndo o risco de criar vontade de ver um filme que (ainda) não existe em vez de despertar a vontade de ler um livro. Com certeza, pode funcionar em alguns casos, especialmente quando um texto apresenta carcterísticas intermidiais tão intensas como A guerra dos bastardos.

Ao analisar o trailer um só personagem aparece se lavando as mãos e uma faca cheias de sangue. Logo aparece a tela em preto as seguintes palavras em branco “UM PUNHADO DE BASTARDOS", continua o personagem se lavando, agora com esponja, e segue a palavra escrita "RENEGADOS", segue uma imagem de algo (um morto, talvez) em saco de plástico preto. O personagem desta vez com chapéu acendendo um cigarro. Segue o texto "E DEGENERADOS", agora o personagem limpando algo, e mais texto "MUITO TRABALHO SUJO A FAZER", o personagem segura uma mão de mulher que coloca com os pacotes em plástico, "E A COISA SÓ VAI PIORAR", o personagem fechando uma mala, "INTELIGENTE, DIVERTIDO, KITSCH", o personagem se vestindo em frente do espelho e "A GUERRA DOS BASTARDOS" (com inversão súbita de cores), segue o personagem vestindo-se, "ROMANCE DE ANA PAULA MAIA" (muda o fundo de cinzento a vermelho e volta, rapidamente), o personagem com a mala feita, comendo cereal do pacote e uma imagem do livro da editora Língua Geral, outra vez o personagem tentando transportar a mala e “NAS LIVRARIAS". Agora, ouve-se o primeiro som da cena com o protagonista: um fechar de porta, acompanhado por um "BLAM!" tipo banda desenhada em vermelho. Depois de se fechar a porta aparece "TRANCADA POR DENTRO", o protagonista desesperado procurando a chave, outra vez em linguagem de Comics a onomatopoesia "PUTZ!” e a 
imagem da chave do carro na mesa, com 'pós-título' "A CHAVE DO CARRO...". Segue outra vez o emblema da Editora e os créditos do trailer. Durante o trailer inteiro, não se ouve nada daquilo que acontece com o personagem, somente a porta. O trailer inteiro está acompanhado por música que lembra os filmes de Alfred Hitchcock ou o film noir e que sublinha a dramaturgia da trama. $\mathrm{O}$ texto interposto lembra o filme mudo e a estética do trailer um pouco 'suja' lembra os filmes Grindhouse dos anos 60 e 70 que foram parodiados por Quentin Tarantino e Robert Rodríguez em tempos recentes. Grindhouse se refere principalmente à má qualidade tanto do próprio filme como do cinema que o mostra. Esse tipo de 'mau gosto' em paródia parece ser o modelo estético do trailer. Sem ser especialista na estética cinematográfica, não é possível entrar em uma análise profunda do trailer, mas será possível afirmar que a proximidade a Quentin Tarantino, que na página de Wikipédia ${ }^{15}$ de Ana Paula Maia é mencionado como modelo que influenciou tanto a autora como sua literatura, salta à vista. Também chamam a atenção a quantidade de referências cinematográficas que cabem em um trailer de pouco mais de um minuto.

\section{Conclusão: “Qual realidade veio primeiro?"16}

A proximidade do texto a outros meios de comunicação, especialmente o filme, se mostra em inúmeras passagens do livro e inclusive vai além do literário, entrando propriamente dito no âmbito cinematográfico, se consideramos o trailer como tipo de

\footnotetext{
15 "Influenciada por Dostoievsky, pelo cinema de Quentin Tarantino, irmãos Cohen e Sergio Leone; e por leituras de obras filosóficas como os diálogos de Platão, Schopenhauer e textos teatrais de Nelson Rodrigues (principalmente no período em que estudou na CAL - Casa de Artes de Laranjeiras - por um período de seis meses) Os personagens de Ana Paula Maia carregam em si uma essência de maldade e fraternidade elevados em potência máxima ao longo de suas narrativas. O belo e o imperfeito ganham novas dimensões em sua literatura." Wikipédia, página de Ana Paula Maia em português http://pt.wikipedia.org/wiki/Ana_Paula_Maia, Acedido em março de 2014.
}

${ }^{16}$ p. 242.

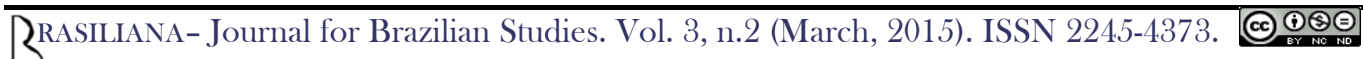


'extensão' do livro. Voltando à hipótese principal, esses recursos inter- e transmidiais criam um efeito que pode ser chamado de 'efeito do medial' em analogia ao 'efeito do real' de Roland Barthes. Em todas as passagens do livro que citam ou evocam ou encenam outros meios essas evocacões guiam a recepção levando a uma leitura 'cinematográfica' durante a qual o leitor 'vê', 'sente' e 'ouve' aquilo que é inserido ou evocado no discurso narrativo. Dado à natureza das referências intermediais, cujos referentes práticamente todo mundo conhece, a experiência sensorial e cinematográfica é possível. As diversas partes do texto que oferecem uma (meta-) reflexão sobre o ficcional contribuem a esse efeito do medial. Na realidade literária, Gina, única protagonista feminina, forte, brutal e bela, vai ao cinema para ver o filme Acossado (A bout de souffle) de Jean-Luc Godard. Aqui, a Menção de sistema é explícita e segue-se uma reflexão sobre o filme e a medialidade em si:

“Termina por entrar numa sessão de cinema que exibe o filme Acossado de Jean-Luc Godard. Nunca tinha assistido a um filme dele, não sabe de que se trata (...). Horácio havia contado tudo o que sabia sobre Amadeu e lá estavam muitas dúvidas. "Não adianta explicar certas coisas que, por mais fictícias que pareçam, são mais reais do que eu e você", foi o que disse Horácio. "Qual realidade veio primeiro?”, questionou Gina, em silêncio. (...) Quando termina o filme, de alguma forma, seus crimes estão estampados ali e a última cena é para ela o início de sua própria história. Enquanto na tela tudo termina com uma morte, uma morte denunciada, traída, para ela a morte foi o começo de tudo. O mais cruel é que em ambos os casos havia o intrínseco desejo de provar o amor, de salvá-lo como uma morte tanto no fim quanto no início. E de quem haveria de ser a culpa?" (pgs. 242-243) 
Esta reflexão, levada a cabo por meio de Gina, mostra outra vez, a proximidade do discurso narrativo literário com os discursos fílmicos que atravessam o texto. A confusão entre o mundo 'real' (literário) e o mundo do filme que Gina propõe é prova do efeito do medial. Por meio da reprodução de imagens e tramas fílmicas, de músicas com ou sem texto, entre outros ${ }^{17}$, se repete a referência a várias tradições, gêneros e recursos estéticos de filme que todo leitor conhece, pelo menos parcialmente. Repetindo essa referência de muitas e variadas formas durante todo o texto, se produz uma contaminação fílmica do meio literário que resulta em 'efeito do medial'. Por meio desse efeito, a obra de Ana Paula Maia cria cria a sensação de estarmos vendo um filme e não lendo um livro quando se abrem as páginas de A guerra dos bastardos.

\section{Bibliografia}

Barthes, Roland. L'effet de réel. Em: Communications, 11, 1968. pgs.84-89.

Barthes, Roland. Der Wirklichkeitseffekt. Em: Das Rauschen der Sprache. Kritische Essays IV. Aus dem Französischen von Dieter Hornig. 2006, Suhrkamp Verlag. pgs.164-172.

Felten, Uta; Maurer-Queipo, Isabel em colaborção com Alejandra Torres. Intermedialität in Hispanoamerika: Brüche und Zwischenräume. 2007, Stauffenberg Verlag.

Herlinghaus, Herrmann. Intermedialität als Erzählerfahrung. Isabel Allende, José Donoso und Antonio Skármeta im Dialog mit Film, Fernsehen, Theater. 1994, Peter Lang Verlag.

\footnotetext{
${ }^{17}$ No presente artigo somente foi possível analisar certa quantidade de referências intermidiais, e dado ao tema, as intetextualidades (com Dostoiévski e Cervantes, entre outros) não foram pesquisadas e analisadas.
} 
Hicketier, Knut. Einführung in die Medienwissenschaft. 2. Auflage. 2010, Metzler Verlag.

Horácio, Luiz. A guerra dos bastardos. Em: O Lobo. O Pasquim de Fausto Wolff e amigos na web. Literatura. Sem data. Acedido em março de 2014.

Klengel, Susanne; Quandt, Christiane; Schulze, Peter W.; Wink, Georg (eds.). Novas vozes. Zur brasilianischen Literatur im 21. Jahrhundert. 2013, Iberoamericana-Vervuert.

Maia, Ana Paula. A guerra dos bastardos. Rio de Janeiro: Língua Geral, 2007.

Rajewsky, Irina O. Intermedialität. 2002, UTB.

Trailer do livro A guerra dos bastardos. Realizado por O Crepúsculo. Disponível em www.youtube.com/watch?v=UhJuLghrrH8. Acedido em março de 2014. 